\title{
ZONEAMENTO AMBIENTAL COMO INSTRUMENTO DE USO E OCUPAÇÃO DO SOLO DO MUNICÍPIO DE AQUIRAZ-CE*
}

\author{
ENVIRONMENTAL ZONING AS THE WAY TO USE AND OCCUPATION FROM \\ THE LAND FROM AQUIRAZ-CE
}

\author{
ZONIFICACIÓN AMBIENTAL COMO INSTRUMENTO DE USO DE LA TIERRA Y \\ LA OCUPACIÓN DE LA CIUDAD DE AQUIRAZ-CE \\ José Lidemberg de Sousa Lopes - Universidade Federal do Ceará - Fortaleza - Ceará - Brasil \\ jlidemberg@yahoo.com.br
}

Luiz Antonio Cestaro - Universidade Federal do Rio Grande do Norte - Natal - Rio Grande do Norte - Brasil

cestaro@ufrnet.br

Fátima Maria Soares Kelting - Universidade Federal do Ceará - Fortaleza - Ceará - Brasil

doninha@ufc.br

\begin{abstract}
Resumo
A Região Metropolitana de Fortaleza (RMF) é composta por quinze municípios, destacando-se entre eles Aquiraz, que possui uma excelente estância balneária e grande importância em razão de seus aspectos socioculturais e históricos. Foi uma das primeiras vilas e primeira capital do Ceará, fundada em 1699 e com sede administrativa da capitania do Siará-Grande até 1726. 0 crescimento urbano local, que vem ocorrendo de forma desordenada nas últimas décadas, em virtude da inserção da indústria do turismo ao longo do litoral cearense, é incompatível com a baixa capacidade de suporte do meio natural, configurando-se insustentável e degradante do meio ambiente. 0 objetivo deste trabalho foi o planejamento adequado do uso e da ocupação do solo de Aquiraz e isso inferiu no zoneamento ambiental da área, baseado na gerência dos interesses e das necessidades sociais e econômicas em consonância com a preservação do meio ambiente e as características naturais do município. Para atingir o objetivo pretendido, foi feita pesquisa bibliográfica sobre o tema zoneamento, coleta de dados censitários de órgãos públicos, trabalho de campo e preparo de material cartográfico como imagem de satélite SPOT (2002) para a confecção do mapa síntese de zoneamento ambiental desse município.

Palavras-chave: zoneamento ambiental, uso e ocupação do solo, unidades ambientais, município de Aquiraz, Estado do Ceará.
\end{abstract}

\section{Abstract}

The region Metropolitan of Fortaleza (RMF) is built up from fifteen counties, by highlighting among them Aquiraz. The county has an excellent resort water place and ample amount of money because of your appearances socialcultures and historic. It went one of first boroughs and first principal city from Ceará, being founded well into 1699 and central administrative from the capitals from Siará - Grande as far as the year of 1726. The growth urban local, that come occurring at it forms unordered at the last decades, well into feature , from the insertion from the tourism industry through the year seashore cearense, is incompatible with the low capacity as of brace from the environmement in situ, in case that unbearable and based from the environmement. The main objetivo of this I work it was the planning to use and avocation from the land of Aquiraz, and It means the environmental zoning from the Area, based at the interests and the socials and economics needs on the basis of the conservation from the environmement and the characteristics in situ from the county. The search it uses - in case that for reaching the one objective pretended, research bibliographic above the zoning, data censitários

\footnotetext{
* Bolsista da FUNCAP (Fundação Cearense de Apoio ao Desenvolvimento Científico e Tecnológico).
} 
from organs public , field job and hardware cartographic as a satellite image SPOT (2002) for the concoction from the chart synthesis as a environmental zoning from the county of Aquiraz from Ceará.

Key words: Environmental Zoning, use and occupation from the land, environmental unities, county of Aquiraz, Ceará State.

\section{Resumen}

La Región Metropolitana de Fortaleza (FMR) se compone de quince municipios, entre ellos Aquiraz. La ciudad cuenta con un recurso excelente y la importancia de un gran spa, debido a sus aspectos socioculturales e históricos. Fue una de las primeras aldeas y la primera capital de Ceará, que se fundó en 1699 y la sede administrativa de la capitanía de Siar-Large en el año 1726. El crecimiento urbano local que se ha producido de manera desordenada en las últimas décadas, debido a la inserción de la industria del turismo a lo largo de la costa de Ceará, es incompatible con la baja capacidad de carga del medio natural, llegando a ser insostenible y la degradación del medio ambiente el medio ambiente. El objetivo de este estudio fue la adecuada planificación del uso y ocupación de Aquiraz, y esta zonificación inferirse ambiental en la zona, en base a los intereses de la administración y las necesidades sociales y económicas compatibles con la preservación del medio ambiente y las características naturales el municipio. La investigación se realizó para lograr el objetivo deseado, la literatura sobre el tema de zonificación, los datos del censo de los organismos gubernamentales, el trabajo de campo y material cartográfico, como la imagen del satélite SPOT (2002) que prepare una síntesis del mapa de zonificación ambiental de la ciudad de Aquiraz en Ceará. Palabras clave: Ordenamiento ambiental, uso de la tierra y el suelo, unidades ambientales, de la ciudad de Aquiraz, Estado de Ceará.

\section{Introdução}

O zoneamento ambiental é um dos instrumentos da Política Nacional do Meio Ambiente do Brasil (Art. 9º inciso II da Lei n. 6938/81), o qual institui que o zoneamento é um princípio, uma norma e uma regra para políticas públicas de qualquer região voltadas para a promoção do uso sustentável dos recursos naturais e para a conservação, proteção e o fomento das condições ambientais e sociais da população. Nessa perspectiva, esta pesquisa se propôs a utilizar esse instrumento para contribuir de forma significativa para a melhoria da qualidade de vida dos habitantes do município de Aquiraz, no Estado do Ceará.

O processo de uso e ocupação das terras por especuladores imobiliários, para fins de atividades turísticas, modifica as paisagens naturais de vários lugares, e o município de Aquiraz está nesse meio, pois a maior parte das localidades ocupadas desordenadamente está na zona litorânea e, como sabemos, os sistemas ambientais formadores do litoral são bastante instáveis.

Ao longo da costa do município, observa-se esse tipo de problema e, sem um planejamento prévio de expansão urbana, as comunidades locais sofrem problemas como a ocupação das zonas de praias, de dunas, 
de falésias, e a contaminação das águas superficiais ou subsuperficiais encontradas nessa área. Além do mais, ainda enfrentam difíceis questões de cunho social como drogas, prostituição, vendas de suas moradias dentre outros.

A estruturação do zoneamento ambiental (Brasil, 1981), instrumento da Política Nacional do Meio Ambiente, consiste no procedimento de divisão de determinado território em zonas ou áreas em que se autorizam determinadas atividades ou se interdita, de modo absoluto ou relativo, o exercício de outras atividades, em razão das características ambientais e socioeconômicas do local (Machado, 2003). Assim, instrumentos de projeto urbano são instituídos em diversas zonas para as quais o Poder Público estabelece regimes especiais de uso e aproveitamento para a sua melhoria e recuperação, o que contribui para uma utilização sustentável do meio ambiente e implica, indiscutivelmente o bem-estar da população.

Salienta-se, ainda, que o zoneamento constitui-se num sistema de identificação e na delimitação de unidades ambientais em um determinado espaço físico, segundo suas vocações e fragilidades, seus acertos e conflitos, estabelecidos com base nos elementos que compõem o meio planejado (Lopes, 2006). Seu resultado é a apresentação de um conjunto de unidades, cada uma sujeita a normas específicas para o desenvolvimento de atividades e a conservação do meio.

Isso demonstra que o zoneamento é um recurso estratégico amplo de planejamento urbano em que são analisados diversos atributos sociais, ambientais, econômicos e institucionais de territórios com o fim de propor alternativas de usos para a reestruturação dessas áreas, para que seja definida uma nova visão institucional do sistema nacional de planejamento.

Para Santos (2004, p. 132), o zoneamento é a compartimentação de uma região em porções territoriais, obtidas pela avaliação dos atributos mais relevantes e de suas dinâmicas. Cada compartimento é apresentado como uma "área homogênea", ou seja, uma zona (ou unidade de zoneamento) delimitada no espaço, com estrutura e funcionamento uniforme. Cada unidade tem, assim, alto grau de associação dentro de si, com variáveis solidamente ligadas, mas significativa diferença entre ela e os outros compartimentos. Isso pressupõe que o zoneamento faz uma análise por agrupamentos passíveis de ser desenhados no eixo horizontal do território e numa escala definida. 
Carneiro e Coelho (1987, p. 38) reforçam que o zoneamento é um instrumento para ordenação de subespaço, o qual emerge basicamente de um conjunto de intenções e atitudes que, contratado com a dinâmica dos processos naturais e sociais ocorrentes nesse subespaço, vai permitir a obtenção de princípios e parâmetros relativos à sua utilização. Tais princípios e parâmetros conduzirão à formulação de normas e procedimentos a uma adequada articulação de meios, a fim de discriminar espaços a utilizar e a não utilizar.

Conforme indagações anteriores, podemos concluir acrescentando que o zoneamento funciona, em especial, como instrumento de planejamento territorial visando ao desenvolvimento sustentável e ao uso adequado do território. Isso porque a divisão de determinado território em zonas, com diferentes usos, ajudará em estudos ambientais e socioeconômicos e de negociações democráticas entre órgãos públicos, setores privados e a sociedade civil sobre estratégias e alternativas que serão adotadas para que se alcance o objetivo maior desse instrumento: a promoção do desenvolvimento sustentável.

Apesar de o zoneamento ser resultado de um processo político-administrativo, os conhecimentos técnicos e científicos - bem como a participação de outros setores (privados e a sociedade civil) - são imprescindíveis para a sua adequação à realidade ambiental e socioeconômica da(s) área(s) a ser(em) zoneada(s) e também pela possibilidade de sua execução em plenitude.

Foi nessa perspectiva que a pesquisa se preocupou em fazer um zoneamento no município de Aquiraz, trabalho que poderá contribuir igualmente para o poder público municipal, em relação ao controle do uso e da ocupação do solo, e para o gerenciamento de atividades que mais se relacionam com cada zona implementada no mapa final desta pesquisa.

\section{Área de estudo e metodologia da pesquisa}

Aquiraz, localizado no litoral leste do Estado, pertencente à Microrregião de Fortaleza, possui área territorial de 482,56 km² (IBGE, 2010), está situado a $3^{\circ} 54^{\prime} 05^{\prime}$ ' de Lat (S) e 38 $23^{\prime}$ 28” de Long (WGr) (IPECE, 2010), limitando-se ao norte com o município de Eusébio; ao sul, com o município de Pindoretama e Cascavel; a leste, com o Oceano Atlântico; a oeste, com o município de Itaitinga (Figura 1). 
A população municipal, segundo o Censo 2010, do IBGE, é de 72.628 habitantes, sendo 67.083 concentrados na área urbana e 5.545, na zona rural.

O clima é um dos componentes físicos de maior hierarquia para caracterizar e ordenar as paisagens. Facilita o entendimento referente aos outros componentes, sejam eles físicos ou bióticos. O estudo climático busca esclarecer a influência desse elemento na vida, na saúde, na distribuição e nas atividades humanas da área planejada.

Segundo o IPECE (2010), a temperatura média do município está em torno de $27^{\circ} \mathrm{C}$, a umidade relativa do ar é de $78 \%$, o tempo de insolação 269,4 dias/ano, com velocidade média anual dos ventos de $3,6 \mathrm{~km} / \mathrm{h}$, os quais são fracos no período das chuvas - que vai de dezembro a abril -, e fortes no período de estiagem, entre os meses de maio e novembro.

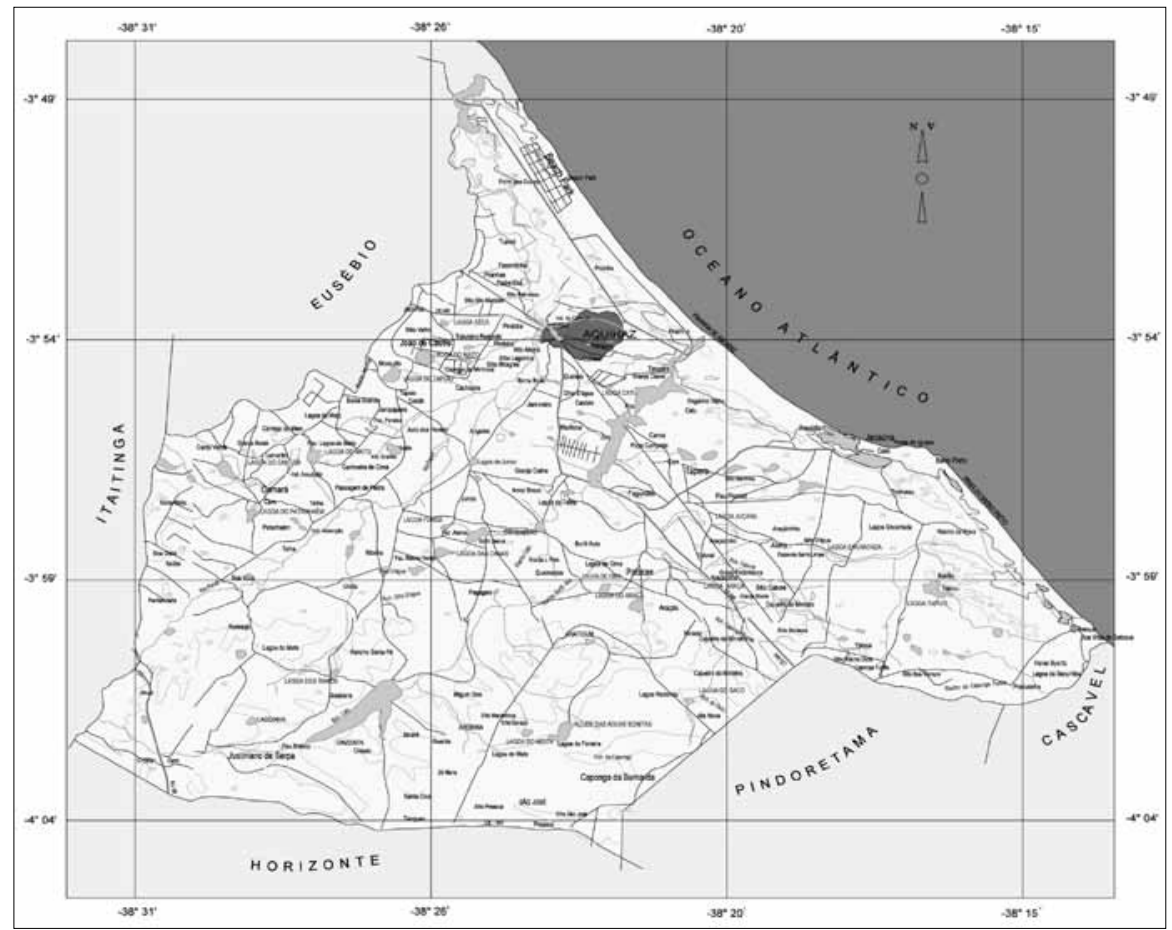

Figura 1 - Mapa de localização do município de Aquiraz-Ce

Fonte: LOPES (2006). 
A geologia/geomorfologia do Município de Aquiraz é composta por rochas pré-cambrianas, granitos, que afloram na região da praia do Barro Preto, por sedimentos tércio-quaternários da Formação Barreiras, que se apresentam como tabuleiros pré-litorâneos e surgem próximo ao litoral, onde formam patamares escalonados recuados entre 50 a 200 metros da praia, no sentido NE-SW, acompanhando o sistema de falhas que corta o Estado do Ceará.

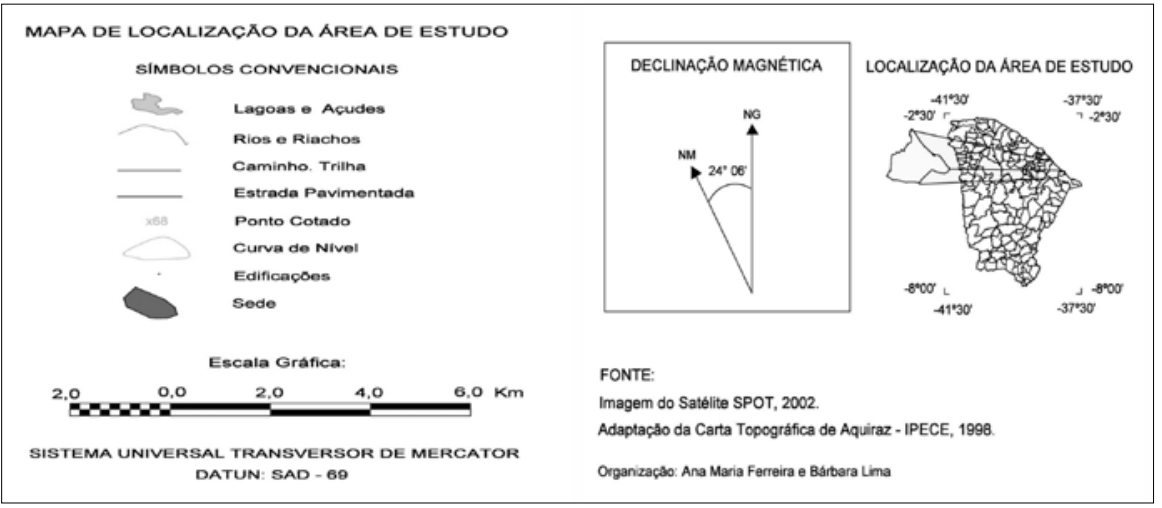

Segundo Carvalho, Coutinho e Morais (1994, p. 55), a geologia/ geomorfologia de Aquiraz é modelada pelo embasamento de rochas précambrianas de composição quartzítica de uma forma geral recoberta por sedimentos terciários de Formação Barreiras. O acúmulo de sedimentos arenosos quaternários vão formar partes das unidades denominadas planícies litorâneas.

Ao longo da costa, observam-se descontinuidades topográficas, ocasionadas por mudanças eustáticas de soerguimento e rebaixamento da crosta, identificadas por ocasião dos níveis mais elevados dos afloramentos dos sedimentos da Formação Barreiras ou quando seus níveis estão bem próximos ao nível do mar. Ao longo do litoral de Aquiraz, a entrada de sedimentos praiais no continente, nos trechos rebaixados, ocorre acompanhando o posicionamento do tabuleiro pré-litorâneo, fixando-se esses sedimentos quando se deparam com os contatos entre os patamares escalonados. Nesse nível, as dunas são móveis e, ao penetrarem o continente, estendem-se em um cordão de dunas fixas, cobertas por uma vegetação arbustiva densa, evidenciando que sua formação ocorreu no passado, em 
condições climáticas similares às atuais, e que a topografia era próxima ao nível do mar à época, mas que foi soerguida, encontrando-se hoje em planos mais elevados. Conforme Lopes (2006), foram identificadas no município de Aquiraz as seguintes unidades geossistêmicas: 1) depressão periférica úmida; 2) planície sublitorânea; 3) planícies litorâneas; 4) planícies fluviais, conforme Figura 2.

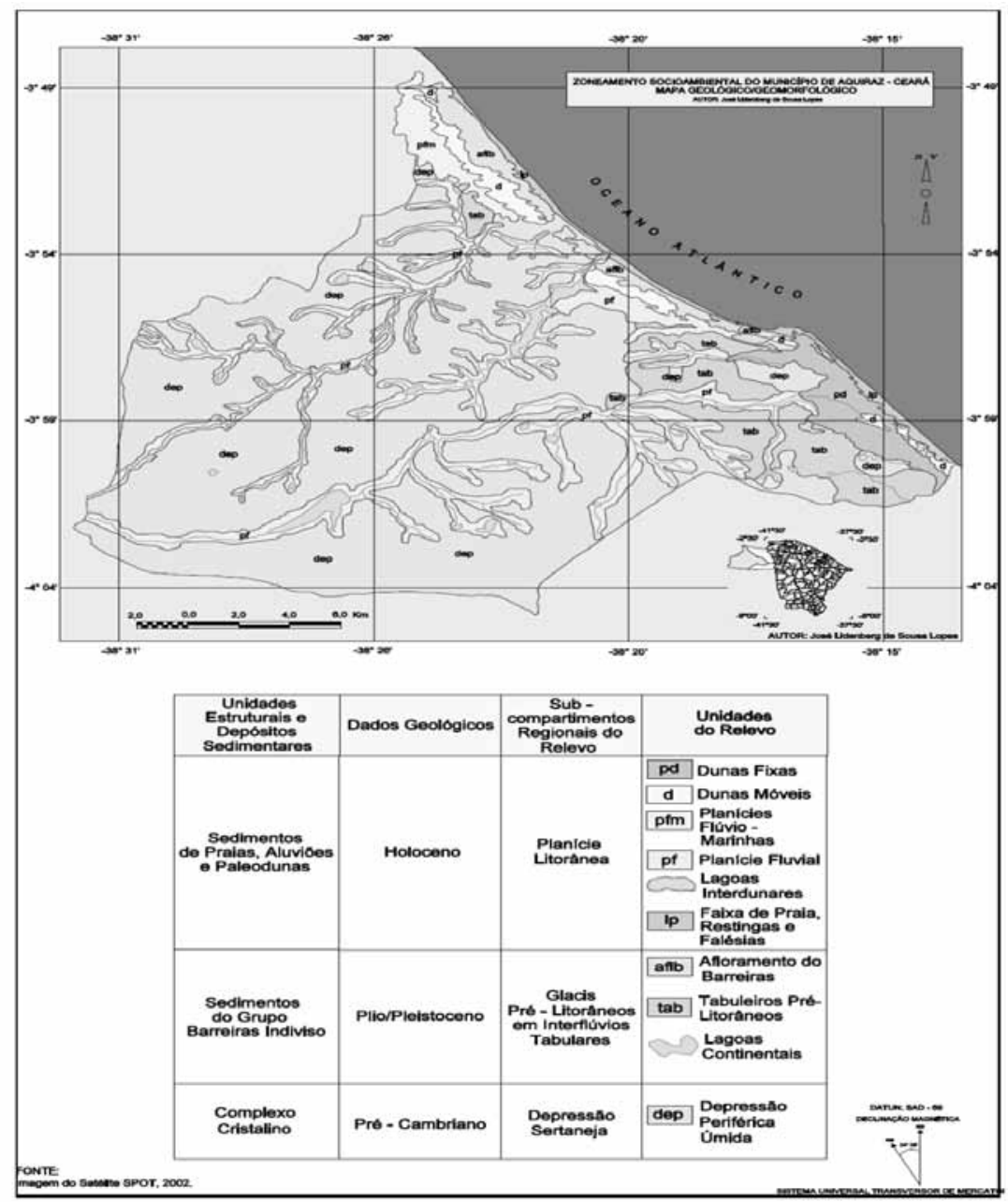

Figura 2 - Mapa Geológico/Geomorfológico do município de Aquiraz-CE Fonte: LOPES (2006). 
A abordagem metodológica utilizada envolveu uma compilação bibliográfica (artigos, dissertações, teses, relatórios técnicos e documentais, bem como sítios da internet) relacionada ao tema abordado. Foram utilizados também, dados estatísticos adquiridos em órgãos públicos - IBGE, IPECE, IBAMA, INCRA, Prefeitura Municipal de Aquiraz - e visita de campo.

Os resultados dos dados obtidos nesses órgãos e o trabalho de campo foram imprescindíveis para a elaboração da parte cartográfica dessa pesquisa, pois com a superposição dos mapas temáticos, gerado a partir do sistema orbital SPOT (2002), escala 1:50.000, composição multiespectral-HRVIR, foi possível efetuar o zoneamento ambiental para Aquiraz.

Tomando-se por base as superposições dos mapas geológico, geomorfológico e pedológico foi efetuado o mapa das condições ambientais, com informações que permitiram identificar as condições do meio natural e suas aptidões.

Com o apoio do mapa das Condições Ambientais, foi superposto o Mapa de Uso da Terra, cujas informações geradas possibilitaram distinguir cinco unidades territoriais de diferentes características que vão determinar normas e ações específicas para cada área em relação ao uso e à ocupação do solo e ao manejo dos recursos naturais, em prol do melhoramento de vida populacional. Essas unidades consistem em áreas passíveis de ocupação, mas com sérias restrições; impróprias à ocupação; propícias à ocupação; utilizadas, mas com as atividades controladas; utilizadas, porém ainda não regulamentadas. Com apoio nessas determinações, definiu-se o zoneamento, para cuja elaboração utilizou-se o soft Microstation SE e o ArcGis 9.2. O mapa foi confeccionado na escala 1:200.000.

\section{Resultados e discussões}

Como resultado desse trabalho, foi elaborado um mapa síntese de zoneamento ambiental do município de Aquiraz (Figura 3), em que foram definidas cinco unidades ambientais, as quais denominaremos Zonas: 1) Zona com sérias restrições à ocupação; 2) Zona imprópria à ocupação; 3) Zona propícia à ocupação; 4) Zona utilizada, mas de ocupação sob controle; 5) Zona utilizada sem regulamentação oficial. Essas Zonas foram fundamentadas nas relações de componentes dos meios físicos, bióticos e socioeconômicos encontrados na área da pesquisa. 
A Zona com restrições à ocupação compreende aquelas áreas em que as unidades ambientais não deverão ser submetidas a empreendimentos imobiliários, por apresentarem propriedades geodinâmica e ecossistêmica em frágil equilíbrio - dunas móveis, lagoas, lagunas continentais, falésias da Formação Barreiras, planícies de inundação dos cursos d'água. Foram definidas como Zona imprópria à ocupação as unidades ambientais como faixa de praia, recifes, falésias, lagos interdunares, paleodunas e planície flúvio-marinhas. Já a Zona propícia à ocupação é constituída de áreas caracterizadas pela presença de tabuleiros pré-litorâneos e depressões periféricas.

A Zona utilizada, mas com ocupação sob controle, é agrupada em duas unidades: a Reserva Extrativista do Batoque (RESEX), criada a partir do Decreto de 5 de junho de 2003, com os objetivos de assegurar o uso sustentável e a plena conservação aos recursos naturais renováveis disponíveis, protegendo os meios de vida e culturais da população local. Essa unidade de conservação ocupa uma área de 601,05 hectares, com perímetro de 13,51 km, localizada entre as coordenadas geográficas de $3^{\circ} 58^{\prime} 30^{\prime \prime}-4^{\circ} 00^{\prime} 50^{\prime \prime}$ de latitude sul e $38^{\circ} 13^{\prime} 20^{\prime \prime}-38^{\circ} 15^{\prime} 10^{\prime \prime}$ de longitude oeste de Greenwich. Como áreas limítrofes, ao norte e a leste, há o Oceano Atlântico; a oeste, a etnia indígena Jenipapo-Kanindé, na Comunidade da Lagoa da Encantada, e as comunidades de Barro Preto em Aquiraz; ao sul, os terrenos da Área de Proteção Ambiental do Balbino, no município de Cascavel, e as localidades dos índios Jenipapo-Kanindé. Vale destacar que o governo federal publicou o relatório final do reconhecimento das terras habitadas por esses índios e, em 24 de fevereiro de 2011, foi assinado o documento que dá plenos poderes à etnia Jenipapo-Kanindé de ser dona de suas terras, notícia recebida com muita satisfação e alegria pela única Cacique feminina do Brasil e toda a etnia.

Por fim, a Zona utilizada sem regulamentação oficial abrange a área em que se situa a localidade das tribos remanescentes de Quilombolas, na lagoa de Ramos/Goaibeiras.

A capacidade de suporte dessas unidades territoriais mantém relações com os principais indicadores ambientais (clima, geologia, geomorfologia, pedologia, recursos hídricos, vegetação, intervenções antrópicas). Dessa forma, as atividades relacionadas à implantação de loteamentos e à expansão dos núcleos urbanos deverão levar em consideração a proteção 
de áreas destinadas ao uso racional do solo do município de Aquiraz, no Estado do Ceará.

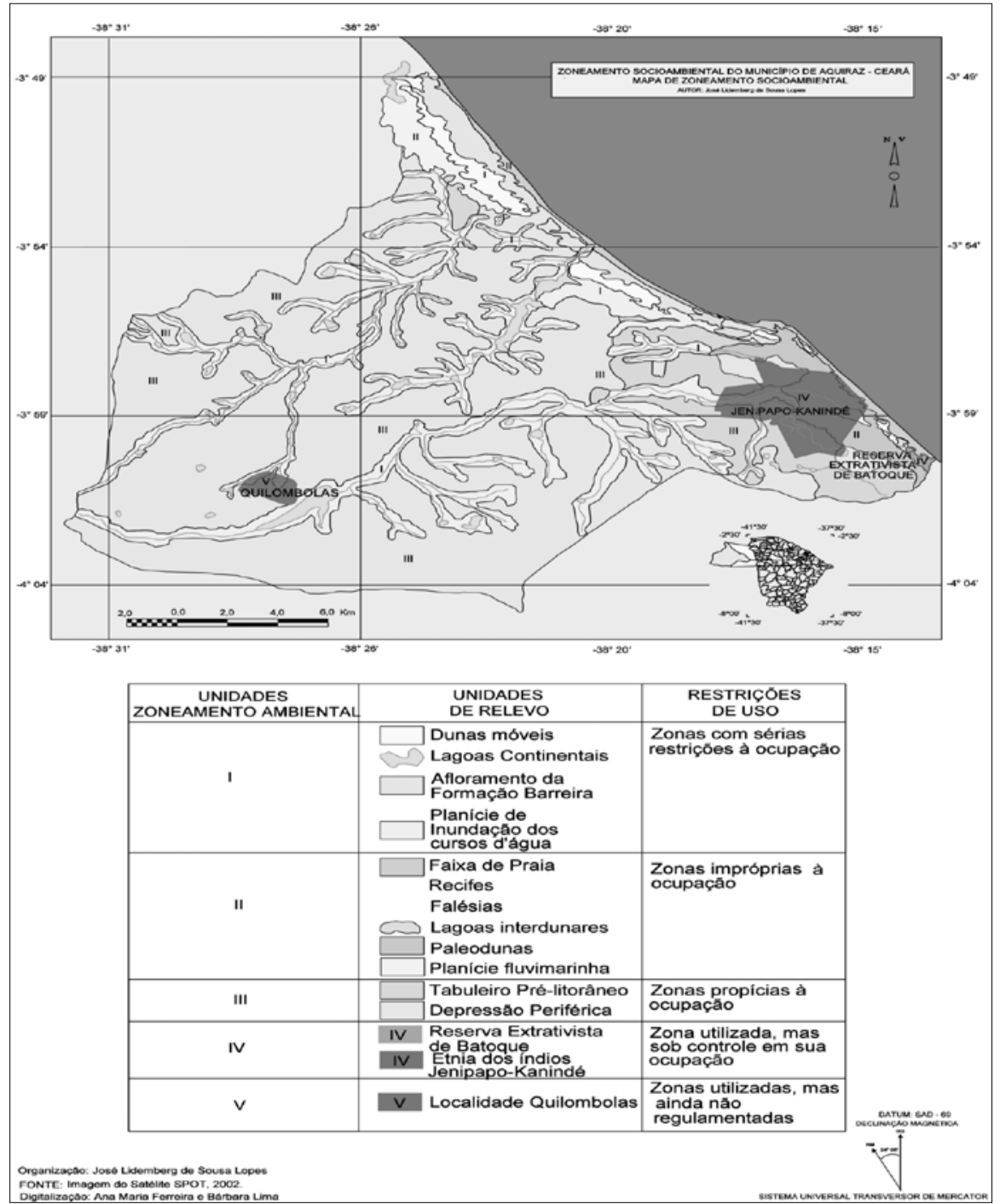

Figura 3 - Mapa do Zoneamento Ambiental do Município de Aquiraz-CE

Fonte: Lopes (2006). 
Artigo

\section{Considerações finais}

Espera-se que esta pesquisa sirva de alerta para as questões aqui abordadas e fortaleça o Plano Diretor de Desenvolvimento Urbano do Município de Aquiraz, que até o presente momento não foi revisado desde a data de sua criação, em 1999.

Acredita-se que os órgãos municipais devam se preocupar com as ocupações do solo futuramente e que o planejamento municipal propicie um crescimento urbanístico mais ordenado, não mais permitindo que haja ocupações aleatoriamente, na busca do desenvolvimento adequado e ecologicamente equilibrado do território, o qual vem sofrendo, nas últimas décadas, vários problemas de cunho socioambiental pelo seu uso subordinado aos desejos e aos parâmetros dos proprietários de terras e dos especuladores imobiliários.

Para a utilização das unidades ambientais atribuídas ao zoneamento ambiental, são necessários estudos prévios intensivos e sistemáticos por intermédio do EIA/RIMA, de acordo com as características dos projetos e da legislação pertinente.

Com isso, o mapa de zoneamento ambiental do município de Aquiraz possibilitará aos administradores municipais a adoção de uma melhor disciplina no uso e na ocupação do solo e, ainda, favorecerá o gerenciamento adequado das atividades socioeconômicas relacionadas ao turismo e ao lazer, de interesse coletivo. As determinações do potencial de suporte de cada unidade ambiental definem os locais ideais para o desenvolvimento urbano, do turismo e do entretenimento da população da região de Aquiraz.

\section{Referências}

BRASIL. Lei n. 6983, de 31 de agosto de 1981. Dispõe sobre a Política Nacional do Meio Ambiente, seus fins e mecanismos de formulação e aplicação e dá providências. Brasília, 1981.

CARNEIRO, C. G.; COELHO, G. B. Método operativo para o planejamento e gestão ambiental. In: Workshop para zoneamento de áreas de proteção ambiental. Anais. Curitiba: IPARDES/SEMA, 1987.

CAVALHO, A. M. de; COUTINHO, P. da Nóbrega; MORAIS, J. O. Caracterização geoambiental e dinâmica costeira da região de Aquiraz na Costa Leste do Estado 
do Ceará. Fortaleza. Revista de Geologia. Depto. de Geologia/UFC, v. 7, p. 55-68, 1994.

INSTITUTO BRASILEIRO DE GEOGRAFIA E ESTATÍSTICA (IBGE). Censo Demográfico Brasileiro. Rio de Janeiro. IBGE, 2010.

INSTITUTO DE PESQUISA E ESTRATÉGIAS ECONÔMICAS DO CEARÁ (IPECE). Fortaleza-CE, 2010.

LOPES, José Lidemberg de Sousa. Zoneamento ambiental no município de AquirazCE. Dissertação (Mestrado) - Universidade Federal do Rio Grande do Norte, Natal, 2006.

MACHADO, Paulo Affonso Leme. Direito ambiental brasileiro. São Paulo: Malheiros, 2003. p. 182.

PLANO DIRETOR DE DESENVOLVIMENTO URBANO (PDDU). Prefeitura Municipal de Aquiraz. Aquiraz-CE, 1999.

SANTOS, R. F. dos. Planejamento ambiental: teoria e prática. São Paulo: Oficina de Textos, 2004.

José Lidemberg de Sousa Lopes - Doutorando em Geografia da Universidade Federal do Ceará.

Luiz Antonio Cestaro - Professor Adjunto da Universidade Federal do Rio Grande do Norte.

Fátima Maria Soares Kelting - Professora Associada II da Universidade Federal do Ceará.

Recebido para publicação em novembro de 2011

Aceito para publicação em fevereiro de 2012 